\title{
Preferences of young women for designing of pouches using Shekhawati motifs
}

\section{Mandeep Kaur, Kanwaljit Brar and Harminder Saini}

Received: 28.02.2018; Revised: 12.10.2018; Accepted: 25.10.2018

See end of the paper for authors' affiliations Mandeep Kaur

Department of Apparel and Textile Science, College of Home Science, Punjab Agricultural University, Ludhiana (Punjab) India

Email : mankaur037@gmail.com
ABSTRACT : The present study on preferences of young women for designing of pouches using Shekhawati motifs was carried out in Ludhiana city. Twenty shapes of pouches were sketched and five shapes were finally selected for designing pouches. A line of twenty pouches using Shekhawati motifs was developed using CorelDrawX4. Preferences of ninety young women, representing the target segment of consumers selected purposively from three localities of Ludhiana city were taken. Women preferred polyester fabric (mean score 4.23) for pouches. Silver and golden colours were most preferred with mean scores 4.34 and 3.14. Respondents preferred multi-coloured combination for motifs (mean score 2.67). Amongst the embellishments, tassels were most liked for pouches with mean score 12.28. Out of twenty developed designs of pouches with Shekhawati motifs, most preferred ten designs of pouches were prepared.

KEY WORDS: Preferences, Young women, Designing, Pouches using, Shekhawati motifs

- HOW TO CITE THIS PAPER : Kaur, Mandeep, Brar, Kanwaljit and Saini, Harminder (2018). Preferences of young women for designing of pouches using Shekhawati motifs. Asian J. Home Sci., 13 (2) : 509-515, DOI: 10.15740/HAS/AJHS/13.2/509-515. Copyright@ 2018: Hind Agri-Horticultural Society. 